Fixed Point Theory, 19(2018), No. 1, 3-12

DOI 10.24193/fpt-ro.2018.1.01

http://www.math.ubbcluj.ro/ ${ }_{\text {nodeacj/sfptcj.html }}$

\title{
AMENABLE LOCALLY COMPACT SEMIGROUPS AND A FIXED POINT PROPERTY
}

\author{
FATEMEH AKHTARI* AND RASOUL NASR-ISFAHANI**
}

Department of Mathematical Sciences, Isfahan University of Technology, Isfahan 84156-83111, Iran

E-mail: f_akhtari@math.iut.ac.ir, isfahani@cc.iut.ac.ir

and

School of Mathematics, Institute for Research in Fundamental Sciences (IPM),

Tehran, P.O.Box: 19395-5746, Iran

\begin{abstract}
For a locally compact semigroup $S$, we study a general fixed point property in terms of Banach left $S$-modules. We then use this property to give our main result which is a new characterization for left amenability of a large class of locally compact semigroups; finally, we investigate several examples which lead us to the conjecture that the main result remains true for all locally compact semigroups.
\end{abstract}

Key Words and Phrases: Banach left $S$-module, foundation semigroup, left amenability, left fixed point, left invariant mean, locally compact semigroup, weak*-operator topology.

2010 Mathematics Subject Classification: 20M30, 28C10, 43A07, 43A10, 46H05, 47H10.

Acknowledgments. The authors would like to express their sincere thanks to the referee of the paper for valuable comments on the paper. They acknowledge that this research was partially carried out at the IPM-Isfahan Branch.

\section{REFERENCES}

[1] A.C. Baker, J.W. Baker, Algebra of measures on a locally compact semigroup III, J. London Math. Soc., 4(1972), 685-695.

[2] J.F. Berglund, H.D. Junghenn, P. Milnes, Analysis on Semigroups, Function Spaces, Compactifications, Representions, John Wiley \& Sons, Inc. New York, 1989.

[3] H.G. Dales, A.T. Lau, D. Strauss, Banach algebras on semigroups and on their compactifications, Mem. Amer. Math. Soc., 205(2010).

[4] M.M. Day, Amenable semigroups, Illinois J. Math., 1(1957), 509-544.

[5] S. Desaulniers, R. Nasr-Isfahani, M. Nemati, Common fixed point properties and amenability of a class of Banach algebras, J. Math. Anal. Appl., 402(2013), 536-544.

[6] J. Diestel, J.J. Uhl, Vector Measures, Math. Surveys Monogr., 15, Amer. Math. Soc., Providence, RI, 1977.

[7] H.A. Dzinotyweyi, The Analogue of the Group Algebra for Topological Semigroups, Pitman Research Notes in Mathematics Series, London, 1984.

${ }^{*}$ The research of the first author supported by a grant from Iran National Science Foundation (No. 94027263). ${ }^{* *}$ The research of the second author was in part supported by a grant from IPM (No. 92430417). 
[8] R.D. Holmes, A.T. Lau, Almost fixed points of semigroups of non-expansive mappings, Studia Math., 43(1972), 217-218.

[9] A.T. Lau, Uniformly continuous functionals on Banach algebras, Colloq. Math., 51(1987), 195205.

[10] A.T. Lau, A.L. Paterson, Inner amenable locally compact groups, Trans. Amer. Math. Soc., 325(1991), 155-169.

[11] A.T. Lau, W. Takahashi, Invariant means and semigroups of nonexpansive mappings on uniformly convex Banach spaces, J. Math. Anal. Appl., 153(1990), 497-505.

[12] A.T. Lau, W. Takahashi, Invariant submeans and semigroups of nonexpansive mappings on Banach spaces with normal structure, J. Funct. Anal., 142(1996), 79-88.

[13] A.T. Lau, W. Takahashi, Fixed point properties for semigroup of nonexpansive mappings on Fréchet spaces, Nonlinear Anal., 70(2009), 3837-3841.

[14] I. Namioka, Fölner's conditions for amenable semi-groups, Math. Scand., 15(1964), 18-28.

[15] A.L. Paterson, Amenability and locally compact semigroups, Math. Scand. 42 (1978), 271-288.

[16] J.P. Pier, Amenable Locally Compact Groups, John Wiley And Sons, New York, 1984.

[17] A. Pourabbas, A. Riazi, Approximate identities in spaces of all absolutely continuous measures on locally compact semigroups, Semigroup Forum, 70(2005), 263-268.

[18] A. Riazi, J.C.S. Wong, Characterizations of amenable locally compact semigroups, Pacific J. Math., 108(1983), 479-496.

[19] S. Saeidi, Ergodic properties of a particular amenable semigroup of mappings in a Banach space, Fixed Point Theory, 10(2009), 321-328.

[20] G.L. Sleijpen, Convolution Measure Algebras on Semigroups, Ph.D. Thesis, Katholieke Univ., The Netherlands, 1976.

[21] G.L. Sleijpen, The dual of the space of measures with continuous translations, Semigroup Forum, 22(1981), 139-150.

[22] J.C.S. Wong, An ergodic property of locally compact semigroups, Pacific J. Math., 48(1973), 615-619.

[23] J.C.S. Wong, A characterization of topological left thick subsets in locally compact left amenable semigroups, Pacific J. Math., 62(1976), 295-303.

[24] J.C. Wong, Fixed point theorems for measurable semigroups of operations, Canad. J. Math., 44(1992), 652-664.

Received: June 11, 2013; Accepted: October 10, 2014. 
